\title{
THIRD HEAD OF BICEPS BRACHII WITH ANATOMICAL CONSIDERATION AND CLINICAL IMPLICATION- A CASE REPORT
}

\author{
M. Mujahid Ansari, U. K. Gupta, M. Laique Ahmed, S. Fayyaz Ali
}

1. Assistant Professor, Department of Anatomy, Dr. S C Govt Medical College, Nanded.

2. Professor, Department of Anatomy, NIMS Medical College. Jaipur.

3. Assistant Professor, Department of Anatomy, Govt Medical College, Aurangabad

4. Assistant Professor, Department of Anatomy, Dr. S C Govt Medical College, Nanded.

\section{CORRESPONDING AUTHOR}

Dr. M. Mujahid Ansari,

C/O Smt. Hidayat Begum, W/O Abdul Razzak, Angle complex, Degloor Naka,

Nanded- 431604, Maharashtra.

E-mail: mohammad_ansari2001@yahoo.com

Ph: 009108421602364

\begin{abstract}
Biceps brachii is a double headed muscle. In terms of number and morphology of its head, it is one of the most variable muscles in the human body. Most common variation is third head, but four, five or even seven heads have been reported. In the present case report third head of biceps brachii was found on the flexor compartment of left arm of an adult female cadaver .The third head of biceps brachii originated from the anteromedial surface of the humerus below the insertion of coracobrachialis and which descended and merged with the other two heads to form common tendon and was inserted on to the radial tuberosity. Third heads might be significant in producing the strong flexion as well as supination of forearm. They may cause compression of neurovascular structures because of their close relationship to brachial artery and median nerve. Variant biceps brachii may confuse a surgeon who performs procedures on the arm and may lead to iatrogenic injuries. The surgeons and traumatologists have to keep such muscular variations in mind.
\end{abstract}

KEYWORDS: Biceps brachii, third head, variation, compression, iatrogenic injuries.

INTRODUCTION: It is well known that the biceps brachii muscle variation are not rare. There is a general idea that it is race dependent. The biceps brachii is one of the muscle of the anterior compartment of the upper arm. It is characteristically described as a two headed muscle that originates proximally by a long head and a short head.In $10 \% 0$ cases a third head arises from the superomedial part of brachialis and is attached to the bicipital aponeurosis , which descends medial side of the tendon of insertion[1].Third head of biceps may present as a group of accessory fascicles arising from the coracoid process, the pectoralis major tendon, head of humerus, articular capsule of humerus or from shaft of humerus itself [2]. The presence of this third biceps head may be important for academic and clinical purpose. Unless symptomatic the third head of biceps brachii may not be detected in clinical studies ${ }^{[3]}$. The third head may provide additional strength to the biceps brachii during supination of the forearm and elbow flexion irrespective of shoulder position [4].Various forms of variations with differing prevalence have been noted in the various reports on various races and ethnicities. Amongst the accessory heads of biceps brachii reported is the presence of 3 to 7 heads [5]. The absence of the long or the short head of biceps brachii muscle and variation in its insertions have also been 


\section{CASE REPORT}

reported. In literature, the prevalence of accessory heads of biceps ranges from $9.1 \%$ to $22.9 \%$ [6].

CASE REPORT: In the present case third head of biceps brachii was found on the left side of female cadaver (Fig-1). The third head of biceps brachii originated from the inferomedial surface of the humerus below the insertion of coracobrachialis. The third head descended and merged with the other two heads to form common tendon (Fig-2) and was inserted on to the radial tuberosity. From the medial margin of the third head a fibrous sheath was observed passing over the neurovascular bundle to join the medial intermuscular septum (Fig-3).Musculocutaneous nerve was seen supplying the third head from its anterior surface (Fig-4). Median nerve was passing with its usual normal course without piercing the third head of biceps brachii. The biceps brachii and neurovascular structure on the arm of right side were found to

be normal.

DISCUSSION: Several articles have reported the incidence of third head of biceps brachii. The biceps brachii muscle presents a wide range of variations. They can manifest as a cluster of accessory fascicles arising from coracoids process, pectoralis minor tendon, proximal head of humerus or articular capsule of humerus [2]. Recently Rodriguez-Niedenfuhr[7] observed 350 arms, classified the supernumerary bicipital heads based on their origin and location. Taking into account all studies and cases reported previously, they defined three different types of supernumerary bicipital heads i.e. superior, inferomedial and inferolateral humeral heads. They observed the presence of a third head in 27 out of 350 (7.7\%) arms. The inferomedial humeral head was observed in 31 out of $350(9 \%)$ arms and was therefore the most common variation. The superior humeral head was observed in five arms (1.5\%). The inferolateral humeral head was the least common variation observed in 1 out of 350 arms $(0.3 \%)^{[8]}$. Earlier workers studied racial differences in different races, among them the supernumerary third head of biceps brachii is found in about 20.5\% South African blacks, $8.3 \%$ of South African whites, $12 \%$ of black Africans, 9\% Brazilian blacks, $20 \%$ of Brazilian white, $8 \%$ of Chinese, $37.5 \%$ of Colombians, $10 \%$ of white Europeans, $18 \%$ of Japanese, $2 \%$ Indian population and $15 \%$ of Turkish ${ }^{[9,10]}$.As far as the side preference for the third head of the biceps brachii is concerned Sweiter and Carmichael emphasized that the incidence of such head is more on the right side, but in our observation it is on left side. ${ }^{[4]}$ Literature review shows the incidence of its occurrence is more in males than females. But Kosogi et al[5] and Asvat et al[6] stated that there are no clear gender and racial differences in the occurrence of supernumerary head of biceps. The presence of a third head of the biceps brachii muscle has its functional and clinical implications. From a functional viewpoint, the humeral origin of the third head of the biceps brachii muscle may contribute to the pronation of the forearm, irrespective of the position of the shoulder joint. Moreover, if the supernumerary heads are relatively large, they may provide additional strength to the biceps tendon. The clinical significance of the third head is its association with the unusual bone displacement which comes subsequent to fracture. Moreover, the supernumerary heads may confuse a surgeon during shoulder operations and such variations, if unilateral, can be a cause of asymmetry between the two arms and hence, can be confused with pathological conditions such as tumours [11]. Variant origin of third head may lead to intramuscular course of musculocutaneous nerve between third and fourth heads, later between third and short heads. Thus it can be a potential site for nerve compression, especially between third and short heads 
during contraction of biceps. This variant course may become more important in hypertrophied biceps brachii muscle in professional weight lifters or body builders. The presence threat to musculocutaneous nerve compression during its passage between supernumerary heads of biceps brachii muscle may pose an additional heads. This possibility is further increased with biceps hypertrophy secondary to its rigorous exercise [12]. Muneuchi et al[13]., Willcox et al[14] and Har-Shai et al[15]. has described that biceps brachii is without doubt a considerable component in plastic surgery but it is known that accessory heads of biceps brachii would be expandable and possibly has more value in flap surgery rather that the two main heads. If the nerve or the vascular structure piercing the accessory head would probably cause difficulty during elevating or transferring the flaps.

MORPHOLOGY AND DEVELOPMENTAL BASIS: Phylogenetically, the variations of the biceps brachii muscle were explained as a remnant of a "tuberculoseptale" head that together with the short and long heads, is present in hylobates, but is a product of regression in humans and anthropoids [16]. Sonntag [17] described the third head of the biceps brachii as a remnant of the long head of the coracobrachialis, an ancestral hominoid condition, particularly in those cases where the third head arose from the insertional area of the coracobrachialis. The supernumerary third head of biceps brachii muscle variation explained in the light of embryogenic development. During the fifth week of development, the mesoderm invades the upper limb bud to further condense in to ventral and dorsal muscle masses. The biceps and triceps musculature is derived from the dorsal and ventral muscle masses of the upper limb buds respectively; it would be during this period of development that accessory muscle may have formed ${ }^{[18] .}$

CONCLUSION: The incidence of third head of biceps brachii is more common in males but in our case cadaver is female. The third heads of the biceps brachii are important for surgeons who perform procedures on the arm and especially for plastic surgeons in flap surgery and clinicians for selective motor nerve blocks and to treat the nerve impairments We believed the third heads observed in the present study might be significant in producing the strong flexion as well as supination of forearm.

ACKNOWLEDGEMENT: I am thankful to Dr. Saleem Basha Tamboli (Associate Professor and Head of Department of Pharmacology, Dr. Shankarrao Chavan Govt. Medical College Nanded) for critical evaluation and proof reading of the manuscript.

\section{REFERENCES}

1. Susan Standring, Grays's anatomy: The anatomical basis of clinica .40 th edition . Churchill Livingstone 2010;6: 825-26.

2. Sargon MF, Tuncali D, Celik HH. An unusual origin for the accessory head of biceps brachii muscle. Clin Anat 1996;9:160-162.

3. Warner JJP, Paletta GA, Warren RF. Accessory head of the biceps brichii: a case report demonstrating clinical relevance. Clin Orthop Rel Res 1992; 280:179-181.

4. Swieter MG, Carmichael SW. Bilateral three headed biceps brachii muscle.

5. Anat Anz 1980; 148: 346-349 
6. Kosugi K, Shibata S, Yamashita H. Supernumerary head of biceps brachii and branching pattern of the musculocutaneous nerve in Japanese. Surg Radiol Anat. 1992; 14: 175185.

7. Asvat, R.; Candler, P. \& Sarmiento, E. E. High incidence of the third head of biceps brachii in South African populations. J. Anat. 182:101-4, 1993.

8. Rodriguez- Niedenfuhr M, Vazquez T, Choi D, Parkin I, Sanudo JR. Supernumerary humeral heads of the Biceps brachii muscle revisited. Clin Anat. 2003; 16: 197-203

9. Kopuz C, Sancak B, Ozbenli S. On the incidence of third head of biceps brachii in Turkish neonates and adults. Acta Anat Nippon. 1999; 74: 301-305.Bergman RA,Thompson SA, Afifi AK. Compendium of Human Anatomic Variations. Baltimore: Urban \& Schwarzenberg, 1988; 139-143.

10. Tountas CP, Bergman RA. Anatomic variation of the upper extremity.NewYork:Churchill Living stone 1993;97-9

11. Prabhjot C.\& Rajan S. Low Incidence of third Head of Biceps Brachii in North Indian Populations: Journal of Clinical and Diagnostic Research. 2011 November (Suppl-2), Vol5(7): 1323-1326.

12. Anjali Aggrawal et al, Four-headed biceps brachii muscle with variant course of musculocutaneous nerve: anatomical and clinical insight; International Journal of Anatomical Variations (2009) 2: 127-130

13. Muneuchi, D.; Suzuki, S.; Ito, O.; Saso, Y. One-stage reconstruction of both the biceps brachii and triceps brachii tendons using a free anterolateral thigh flap with a fascial flap. J. Reconstr. Microsurg., 20:139-42, 2004

14. Wilcox, T.M.; Teotia, S.S.; Smith, A. A. \& Rawlings, J. M., biceps brachii muscle flap for axillary wound converage. Plast. Reconstr. Surg., 110:822-6, 2006.

15. Har-Shai, Y.; Kaufman, T.; Hasmonai, M.; Hirsowitz, B. \& Schramek, A. External longitudinal splitting of the biceps brachii muscle for converage of repaired brachial vassels: an anatomical study and clinical application. 21:158- 68, 1988.

16. de Burlet HM, Correlje J. Uber Variationen des menschlichen Musculus biceps brachii. Gegenbaur's Morphol. Jahrb. 1919; 50: 403-16.

17. Sonntag CF. On the anatomy, physiology and pathology of the chimpanzee. Proc. Zool. Soc. 1923; 22: 323-363.

18. Nayak SR, Krishnamurthy A, Kumar M et al. Four headed Biceps and Triceps brachi muscle, with neurovascular variation Anat.Sci.Lut:2008; 83:107.11

Fig.1 Showing Origin of Biceps Brachii muscle with third head on left female cadaver.

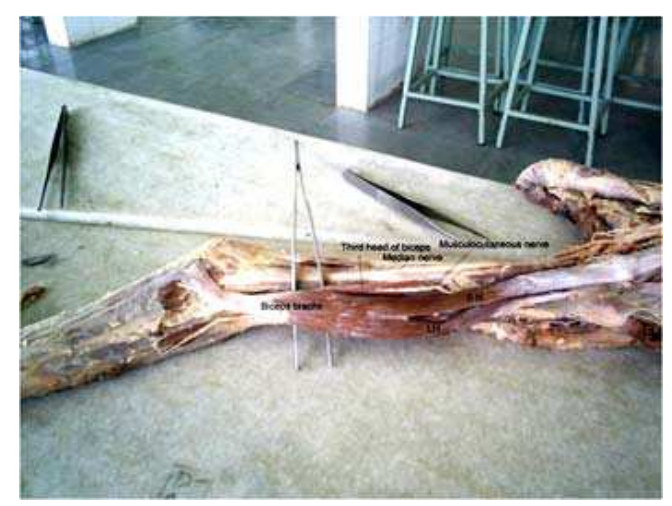




\section{CASE REPORT}

Fig. 2 Showing Fusion of Normal two heads of Biceps with Third head SH-Short Head, LHLong Head

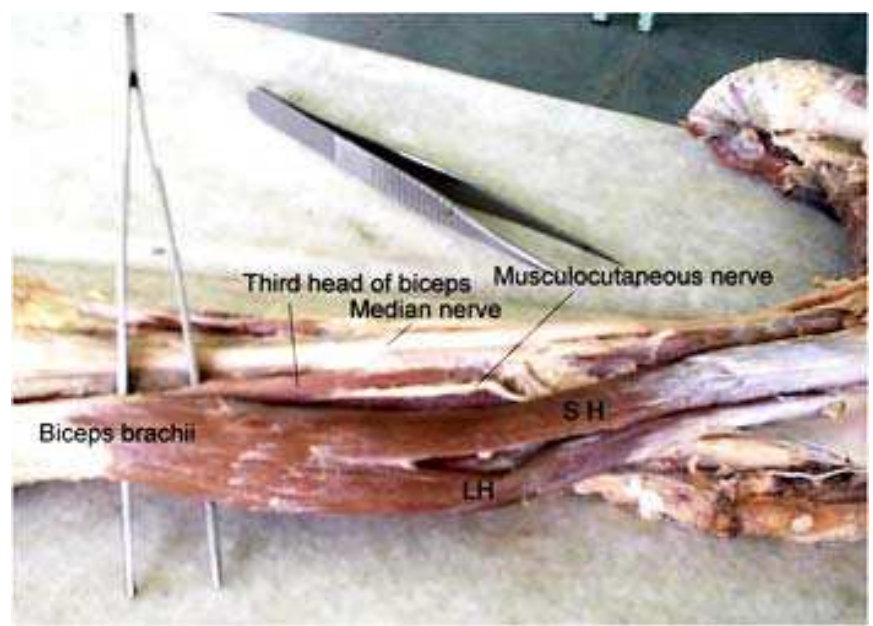

Fig-3 Showing Fibrous sheath coming from tendon of Biceps Brachii before insertion

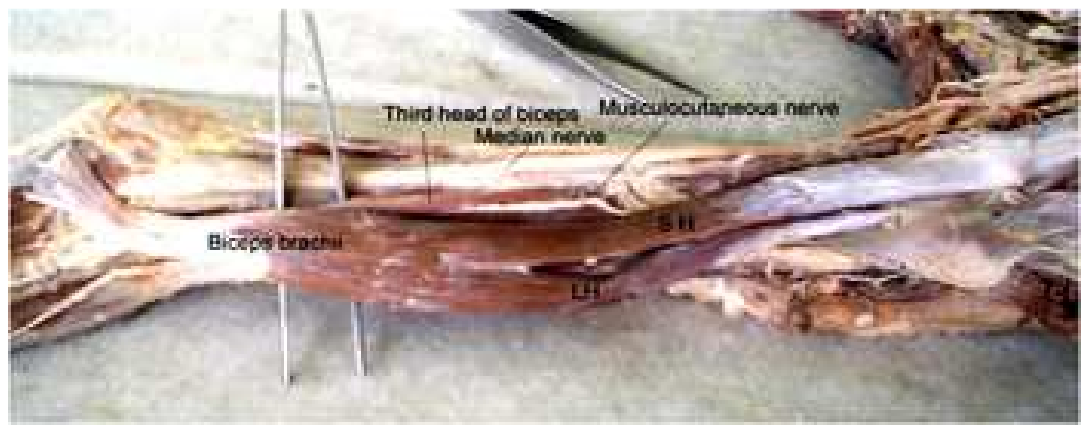

Fig-4 Showing insertion Biceps Brachii with Third Head near and Musculocutaneous nerve

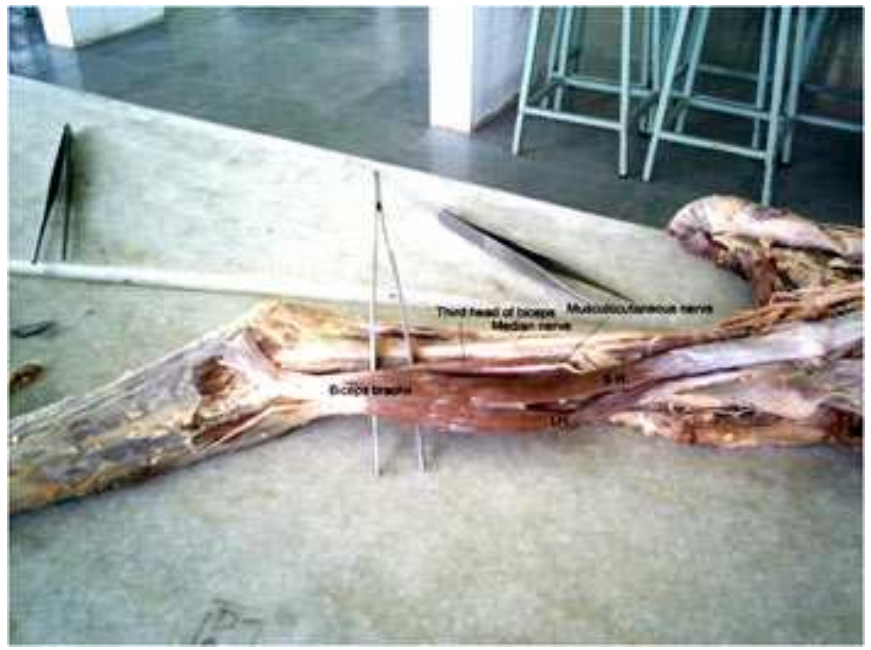

